\title{
Synthetic Fibronectin Peptides Suppress Arthritis in Rats by Interrupting Leukocyte Adhesion and Recruitment
}

\author{
S. M. Wahl, ${ }^{\star}$ J. B. Allen, ${ }^{\star}$ K. L. Hines, ${ }^{\star}$ T. Imamichi, ${ }^{\star}$ A. M. Wahl, ${ }^{\star}$ L. T. Furcht, ${ }^{\ddagger}$ and J. B. McCarthy ${ }^{\star}$ \\ *Laboratory of Immunology, National Institute of Dental Research, National Institutes of Health, Bethesda, Maryland 20892; \\ and ${ }^{\ddagger}$ Department of Laboratory Medicine and Pathology, Biomedical Engineering Center, University of Minnesota, \\ Minneapolis, Minnesota 55455
}

\begin{abstract}
In an experimental model of arthritis, increased leukocyte adhesion is associated with the evolution of acute and chronic synovial inflammation. Whereas peripheral blood mononuclear cells (PBMC) from control animals bind minimally to fibronectin matrices, $P B M C$ from animals receiving arthropathic doses of bacterial cell walls demonstrate increased integrin mRNA expression and enhanced adhesion. To determine whether this augmented adhesion was causal in the development of synovial pathology, peptides synthesized from several fibronectin domains which inhibited leukocyte adhesion in vitro were administered to arthritic animals either as free peptides or coupled to a carrier molecule. Not only were peptides containing either the RGD or CS-1 cell-binding domains inhibitory to chronic synovial pathology (articular index $=\mathbf{1 0 . 5} \pm 0.3$ for untreated animals compared to $1.25 \pm 0.25$ for RGD and $2.5 \pm 0.7$ for CS-1), but three peptides synthesized from the carboxy-terminal 33$\mathrm{kD}$ heparin-binding domain of fibronectin were also found to significantly inhibit leukocyte recruitment and the evolution of arthritis. Based on these data, which are the first to explore the therapeutic potential of heparin-binding fibronectin peptides in chronic inflammation, it appears that antagonism of cellular adhesion and recruitment by fibronectin peptides may provide an important mechanism for modulating the multi-step adhesion process and attenuating aberrant inflammatory responses. (J. Clin. Invest. 1994. 94:655-662.) Key words: inflammation • synovium • integrins $\cdot$ matrix $\cdot$ proteoglycans
\end{abstract}

\section{Introduction}

Cell-cell and cell-matrix interactions are fundamental to embryogenesis, morphogenesis, wound healing, and tumor metastasis. The molecular basis for the adhesion of both normal and transformed cells is complex and involves several distinct cell surface molecules. On leukocytes, selectins, which are carbohydrate-binding lectins (for review see references 1,2 ), members of the Ig superfamily (3), and integrins composed of $\alpha$ and $\beta$ transmembrane glycoproteins $(4,5)$ control their localization

Address correspondence to Sharon M. Wahl, Ph.D., Cellular Immunology Section, Laboratory of Immunology, NIDR, NIH, Bldg. 30, Rm. 331, 9000 Rockville Pike, Bethesda, MD 20892.

Received for publication 2 August 1993 and in revised form 13 January 1994.

The Journal of Clinical Investigation, Inc.

Volume 94, August 1994, 655-662 and recruitment to sites of infection or inflammation. Of the integrins, those containing $\beta_{2}$ subunits (CD18) are largely involved in cell-cell interactions (3), whereas $\beta_{1}$ (CD29) integrins also mediate adhesion to extracellular matrix constituents (3-6). One of these extracellular matrix macromolecules is fibronectin, found in plasma, cell matrices, basal lamina, and on cell surfaces (7).

Fibronectin possesses multiple domains recognized by integrins including arginyl-glycyl-aspartic acid (RGD) ${ }^{1}$ which interacts with $\alpha_{5} \beta_{1}$ (VLA-5), $\alpha_{3} \beta_{1}$ (VLA-3), and other integrins (8, 9 ), and the alternately spliced connecting segment domain (CS1) which is recognized by $\alpha_{4} \beta_{1}$ (VLA-4) (10). In addition to recognizing the CS-1 domain of fibronectin, $\alpha_{4} \beta_{1}$ also serves as a receptor for vascular cell adhesion molecule-1 (VCAM-1), a member of the immunoglobulin superfamily which is rapidly induced on endothelial cells in response to IL-1 and TNF $\alpha$ and increased at sites of inflammation $(11,12)$. Both $\alpha_{5} \beta_{1}$ and $\alpha_{4} \beta_{1}$ are found on mononuclear leukocytes, and adhesion is augmented after activation $(13,14)$. In addition to integrins, cell surface proteoglycans may also contribute to cellular recognition and adhesion events. In this regard, interest has recently focused on polypeptides derived from the 33-kD carboxyl-terminal heparin-binding domain of fibronectin which promotes lymphoid and tumor cell adhesion and spreading by RGD-independent mechanisms $(15,16)$. The proximity of proteoglycanand integrin-binding (CS-1) sites within the 33-kD fragment suggests a potential collaborative interaction between $\alpha_{4} \beta_{1}$ and cell surface proteoglycan receptors (17). Moreover, leukocyte interaction with this RGD-independent fibronectin region implicates a role for recognition of such domains in inflammatory events (18).

In chronic inflammation, dysregulation of leukocyte recruitment may lead to substantial tissue pathology. In an experimental model, administration of bacterial cell wall fragments to genetically susceptible animals results in persistent leukocyte recruitment and inflammation within the synovium (19). Afflicted joints become swollen and deformed as a consequence of the inflammation in the synovial lining with the development of progressive destruction of the extracellular matrices of articular cartilage and subchondral bone. To examine the relevance of specific adhesive interactions in these events, fibronectin peptides containing RGD or CS-1 domains, in addition to unique sequences synthesized from the 33-kD carboxyl-terminal heparin-binding fragment of the A chain, have been tested for their ability to block inflammatory cell adhesion in vitro and the

1. Abbreviations used in this paper: AI, articular index; CS, connecting segment; EDC, 1-ethyl-3 (3-dimethylaminopropyl)-carbodiimide hydrochloride; FN, fibronectin; GAPDH, glyceraldehyde-3-phosphate dehydrogenase; MPA, murine pulmonary artery; OA, ovalbumin; RGD, arginyl-glycyl-aspartic acid; SCW, streptococcal cell walls. 


\begin{tabular}{|c|c|}
\hline Peptide & Sequence \\
\hline RGD & Ile-Thr-Val-Tyr-Ala-Thr-Gly- -Ser-Pro-Ala-Ser-Ser-Lys-Pro-Ile-Ser (1485-1504) * \\
\hline CS-1 & $\begin{array}{l}\text { Asp-Glu-Leu-Pro-Gln-Leu-Val-Thr-Leu-Pro-His-Pro-Asn-Leu-His-Gly-Pro-Glu-Ile-t. } \\
\text {-Pro-Ser-Thr (1961-1985) }\end{array}$ \\
\hline FN-C/H-I & Tyr-Glu-Lys-Pro-Gly-Ser-Pro-Pro-Arg-Glu-Val-Val-Pro-Arg-Pro-Arg-Pro-Gly-Val ${ }^{\ddagger}$ (1906-1924) \\
\hline $\mathrm{FN}-\mathrm{C} / \mathrm{H}-\mathrm{II}$ & Lys-Asn-Asn-Gln-Lys-Ser-Glu-Pro-Leu-Ile-Gly- \\
\hline FN-C/H-IV & Ser-Pro-Pro- : $\quad s^{5}-A l a-A r g-V a l-T h r ~(1784-1792)$ \\
\hline $\mathrm{FN}-\mathrm{C} / \mathrm{H}-\mathrm{V}$ & Trp-Gln-Pro-i: $\quad$-Ile $(1892-1899)$ \\
\hline
\end{tabular}

(Shaded area) Predicted active binding domain. ${ }^{*}$ Residue numbers. ${ }^{\ddagger}$ Active site unknown. ${ }^{\S}$ Based on mutation data (46).

development of inflammation in vivo as evaluated in the bacterial cell wall-induced model of erosive polyarthritis.

\section{Methods}

Fibronectin isolation and peptide synthesis. Human plasma fibronectin (FN) was purified as a byproduct of factor VIII production by sequential ion-exchange and gelatin affinity chromatography, and the tryptic/catheptic 33-kD cell adhesion and heparin binding ( $\mathrm{FN}-\mathrm{C} / \mathrm{H})$ fragment of the fibronectin A chain was isolated (20). Fibronectin polypeptides having sequences within this region were synthesized at the Microchemical Facility of the University of Minnesota using a Beckman system 990 peptide synthesizer (Beckman Instruments Inc., Fullerton, CA) (20). Lyophilized crude peptides were purified by preparative reverse-phase high performance liquid chromatography (HPLC) on a C-18 column, using an elution gradient of $0-60 \%$ acetonitrile with $0.1 \%$ trifluoroacetic acid in water. Peptides were synthesized with a tyrosine residue at the carboxy terminal end to facilitate peptide radioiodination, and the purity and composition of the peptides were verified by HPLC analysis. The sequences of the peptides utilized in the studies are shown in Table I.

Peptide-carrier conjugation. Synthetic peptides were chemically conjugated to ovalbumin (OA; Sigma Chemical Co., St. Louis, MO) using 1-ethyl-3 (3-dimethylaminopropyl)-carbodiimide hydrochloride (EDC) (15). Equal amounts $(2-10 \mathrm{mg})$ of the peptides and OA were solubilized in water $(0.5-2 \mathrm{ml})$ and mixed with a 10 -fold excess (by weight) of EDC dissolved in water $(300 \mu \mathrm{l})$. The sample was mixed overnight at $4^{\circ} \mathrm{C}$ on a circular rotator protected from light. The coupled peptides were dialyzed extensively against sterile phosphate buffered saline (PBS) at $4^{\circ} \mathrm{C}$ to remove excess EDC and uncoupled peptide (Spectrapore 6, 10-kD exclusion; Spectrum Medical Industries, Los Angeles, CA). The molar ratio of each of the peptides to OA was $5: 1$, as determined by using trace amounts of radioactive peptides in the coupling reaction. The conjugates were aliquoted and stored at $-80^{\circ} \mathrm{C}$ until use.

Initiation and treatment of arthritis. Arthritis was induced in inbred female Lewis (LEW) rats (Harlan Sprague Dawley, Indianapolis, IN) with a single intraperitoneal injection of peptidoglycan-polysaccharide fragments $(2.5 \mathrm{mg}$ rhamnose/100 $\mathrm{gm}$ rat) from group A streptococcal cell walls (SCW; ATCC 10389) as described $(19,21)$. The four individual extremities were graded on a scale of 0 (normal) to 4 (maximum erythema, swelling and deformity) daily, or as otherwise indicated, by a single experienced observer and summed as the articular index (AI) which can range from 0 to 16 . For histopathologic analysis, tissue specimens were fixed in $10 \%$ buffered formalin, decalcified in $10 \%$ EDTA, embedded in paraffin, sectioned $(6 \mu \mathrm{m})$, and stained with hematoxylin and eosin.
At the initiation or at selected intervals after the induction of arthritis, synthetic peptides, free or coupled to ovalbumin, were diluted in PBS $(2 \mathrm{mg} / \mathrm{ml})$ and injected i.v. at a dose of $3 \mathrm{mg} / \mathrm{kg}$ daily for $5 \mathrm{~d}$ in 0.5 $\mathrm{ml}$ PBS. Control animals received equal volumes of PBS only or OA conjugated to OA in PBS.

Mononuclear cell preparation and RNA isolation. Peripheral blood mononuclear cells (PBMC) were obtained from control animals and at indicated intervals after the administration of SCW by density gradient (Histopaque 1083; Sigma Chemical Co.) centrifugation of heparinized blood (19). The cells were washed twice in PBS and resuspended in Dulbecco's modified Eagles medium (DME) containing $50 \mu \mathrm{g} / \mathrm{ml}$ gentamicin, and $2 \mathrm{mM}$ glutamine (GIBCO BRL, Gaithersburg, MD) for culture and cell attachment assays.

Total cellular RNA was isolated using a one-step acid guanidinium thiocyanate-phenol-chloroform procedure (22). For Northern analysis, $5 \mu \mathrm{g}$ total RNA was electrophoresed on $1.0 \%$ formaldehyde-agarose gels and transferred to nitrocellulose filters (Schleicher and Schuell, Keene, NH). The blots were prehybridized at $42^{\circ} \mathrm{C}$ for $\geq 4 \mathrm{~h}$ and hybridized overnight with the ${ }^{32} \mathrm{P}$-labeled cDNA probes for rat glyceraldehyde3 -phosphate dehydrogenase (GAPDH) (23) and the $\alpha_{5}$ integrin subunit (Telios Pharmaceuticals, Inc., San Diego, CA). The filters were washed and exposed to a phosphor screen for 8-24 $\mathrm{h}$ and analyzed on a PhosphorImager using Image Quant software (Molecular Dynamics, Inc., Sunnyvale, CA) as described (24).

Cell attachment assays. Cell attachment was determined by a modification of a previously described method (24). Tissue culture chamber slides ( 8 well; Lab-Tek, Nunc, Inc. Naperville, IL) were coated with 1 $\mu \mathrm{g} / \mathrm{well}$ bovine serum albumin (Boehringer Mannheim Biochemicals, Indianapolis, IN), purified fibronectin or fibronectin peptides ( $8 \mu \mathrm{g} / \mathrm{well})$ in $\mathrm{H}_{2} \mathrm{O}$. Gelatin (1\%) (BioRad, Richmond, CA) was added to each well at $37^{\circ} \mathrm{C}$ for $1 \mathrm{~h}$ and aspirated before control or treated PBMC or spleen cells in DME without serum were seeded in replicate wells at a density of $2.0 \times 10^{6}$ cells $/ 0.2 \mathrm{ml}$. After $30 \mathrm{~min}$ at 24 or $37^{\circ} \mathrm{C}$, the unattached cells were removed by two PBS washes, and the attached cells fixed and stained with Diff Quik (Baxter Scientific Products, McGraw Park, IL). In additional assays, murine pulmonary artery (MPA) cells (generously provided by Dr. Una S. Ryan, Washington University, St. Louis, MO) were seeded $\left(250 \mu \mathrm{l} ; 2.5 \times 10^{4} / \mathrm{ml}\right)$ onto chamber slides, cultured $24-48 \mathrm{~h}(\sim 70 \%$ confluent $)$, and stimulated with TNF $\alpha(2.2 \mu \mathrm{g} / \mathrm{ml}$, Genzyme) for $4 \mathrm{~h}$ at $37^{\circ} \mathrm{C}$ before the leukocytes were added (25). Attached leukocytes were quantitated using the Optomax Image Analyzer (Hollis, $\mathrm{NH}$ ) and the numbers of attached cells expressed as the mean \pm SEM. For inhibition of cell adhesion assays, SCW-treated PBMC or spleen cells were cultured at $37^{\circ} \mathrm{C}$ for $15 \mathrm{~min}$ in the presence or absence of the synthetic peptides or their scrambled counterparts (10$100 \mu \mathrm{g} / \mathrm{ml}$ ) before being seeded in replicate wells coated with the 33$\mathrm{kD}$ fibronectin fragment or MPA cells. 

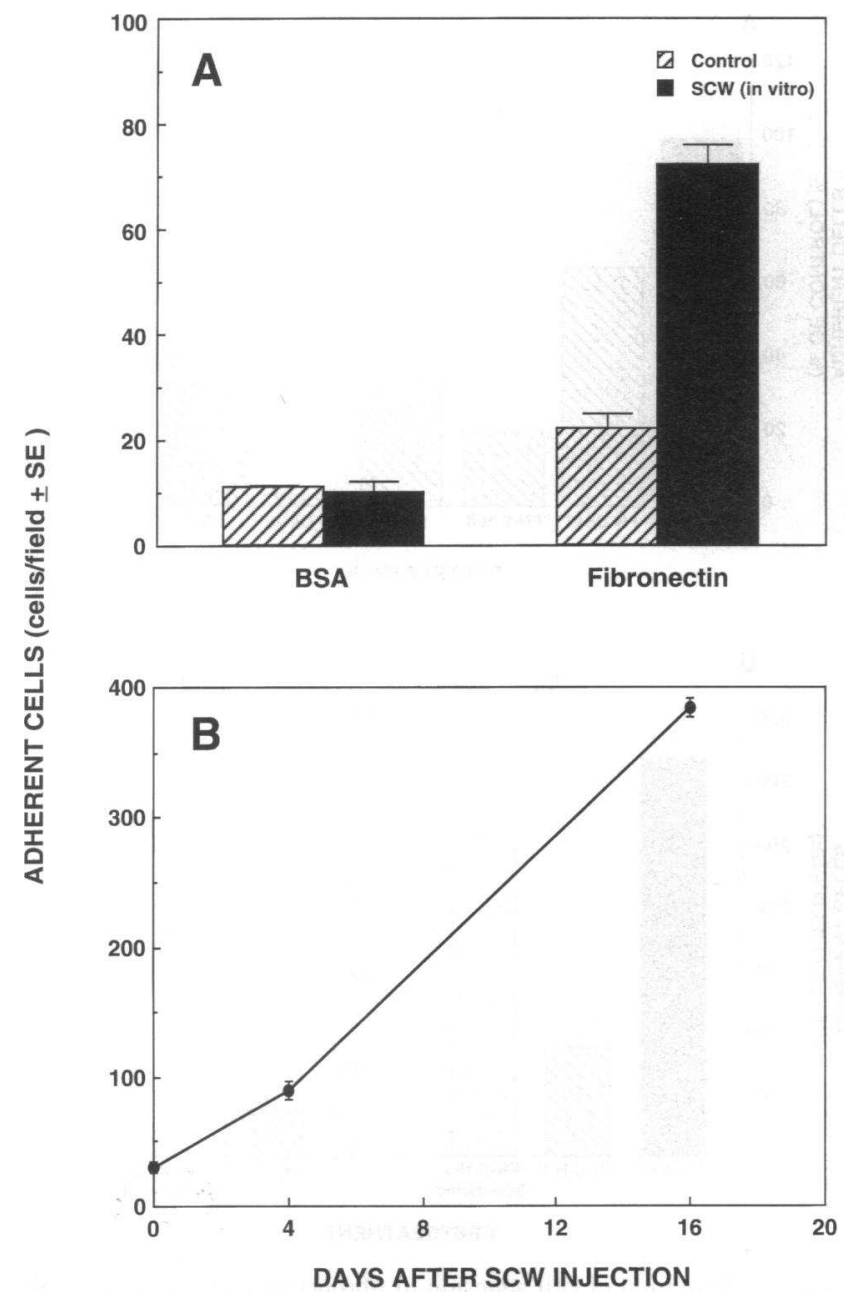

Figure 1. Enhanced matrix adhesion of SCW-activated leukocytes. $(A)$ PBMCs were cultured with SCW $(5 \mu \mathrm{g} / \mathrm{ml})$ for $18 \mathrm{~h}$, washed and assayed for adhesion to fibronectin substrates as defined in Methods. (B) At the indicated intervals after systemic SCW injection in vivo, PBMCs were isolated and directly assayed for binding to fibronectin substrates. Data represent the mean $\pm \mathrm{SE}$ of duplicate assays.

Statistical analysis. Significance of differences between mean values was determined by analysis of variance and Fisher's post hoc analysis for multiple comparisons.

\section{Results}

SCW increases leukocyte adhesion in vitro and in vivo. In initial experiments, PBMC were cultured in the presence or absence of SCW and then evaluated for their ability to adhere to an intact fibronectin matrix. As evident in Fig. $1 \mathrm{~A}$, SCW activation of PBMC in vitro resulted in augmented binding to the extracellular matrix. Moreover, when PBMC were isolated from animals in which arthritis was induced by the systemic injection of SCW, there was a time-dependent increase in the number of circulating adherent cells in equivalent numbers of PBMC (Fig. $1 B$ ). A threefold increase in binding was evident within $4 \mathrm{~d}$ after SCW injection at the peak of the acute inflammatory response (Fig. 1 B). By $16 \mathrm{~d}$ after SCW administration which coincided with the development of chronic inflammation in the synovium and liver (19), the number of adherent PBMC was substantially ( $>10$-fold) higher than controls.

Increased PBMC integrin expression correlates with development of arthritis. To further define the mechanism of SCWmediated cellular adhesion to fibronectin and its potential contribution to the development of inflammation and synovial pathology, PBMC were isolated from animals at intervals from 1-52 d after a single arthropathic dose of SCW, and the RNA extracted and probed by Northern analysis for integrin subunit expression. Gene expression for the $\alpha_{5}$ subunit of the fibronectin receptor $\left(\alpha_{5} \beta_{1}\right)$ was found to increase in the PBMC within 2$3 \mathrm{~d}$ after induction of arthritis (Fig. $2 A$ ), decline between days 5 and 10 , and increase again during chronic inflammation before diminishing as the inflammation stabilizes. When the $\alpha_{5}$ mRNA levels from all time points evaluated were normalized to constitutively expressed GAPDH mRNA and compared to the articular indices of the animals, the changes in $\alpha_{5}$ mRNA expression appeared to precede and parallel the development of the adherent phenotype (Fig. $1 \mathrm{~B}$ ) and of the acute and chronic phases of the erosive polyarthritis (Fig. $2 B$ ).

Effect of RGD peptides on the development of SCW-induced arthritis. The correlation between PBMC integrin gene expression, functional adhesion, and arthritis suggested that RGDspecific binding of leukocytes might be a pivotal mechanism involved in leukocyte homing to the inflamed synovium and

\section{DAYS AFTER SCW INJECTION}

A
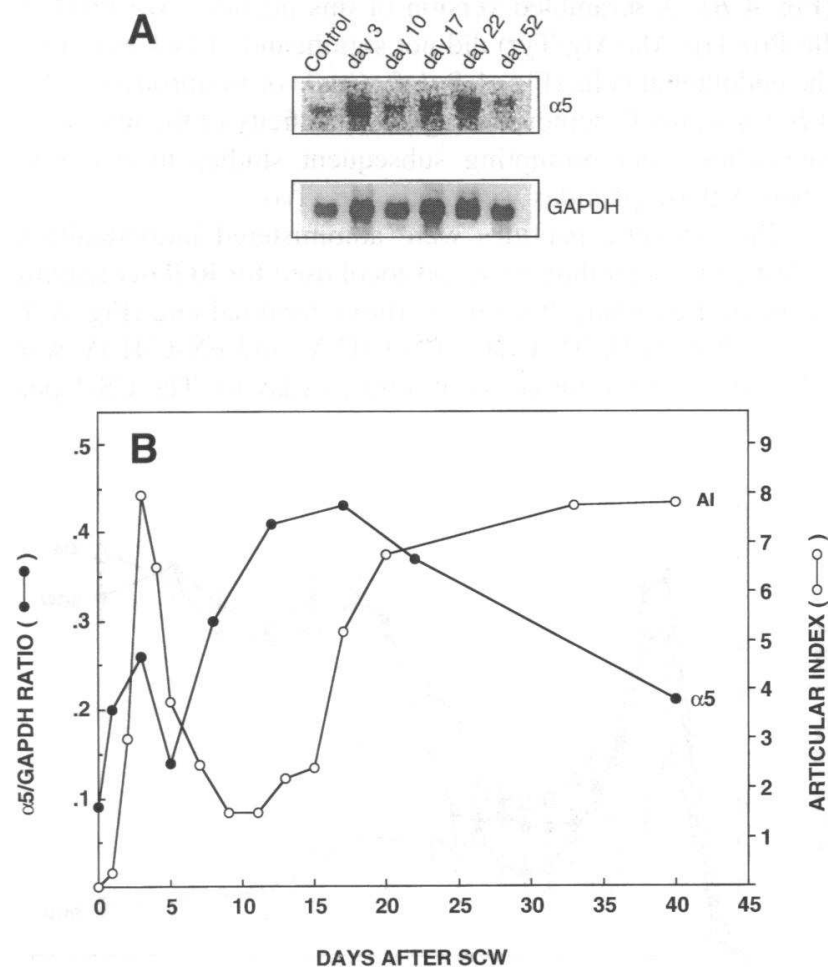

Figure 2. SCW induces increased integrin mRNA expression. (A) PBMC were isolated from control and arthritic animals from 0-52 d after SCW administration. RNA was isolated and $\alpha_{5}$ mRNA expression determined by Northern analysis with the $\alpha_{5}$ cDNA probe. $(B)$ Levels of $\alpha_{5}$ mRNA were normalized to the constitutively expressed GAPDH $\left(\alpha_{5} / \mathrm{GAPDH}\right.$ ratio) and the kinetics of $\alpha_{5}$ expression compared with the articular indices (AI) from day 0 to day 40 after SCW administration. 
that this event might be a target for interrupting this process. To evaluate such a possibility, RGD-containing synthetic peptides (MC-2) were coupled to an ovalbumin carrier and administered ( $3 \mathrm{mg} / \mathrm{kg}$ i.v.) daily for $5 \mathrm{~d}$ to animals receiving an arthropathic dose of SCW, and the clinical course of the lesions monitored by the joint scores (AI) (Fig. 3). A nearly 50\% decline in the acute neutrophil-mediated response was evident on day 3 in animals receiving $\mathrm{RGD}(\mathrm{AI}=5.5 \pm 0.84$ vs. $9.79 \pm 0.33$ for untreated, $P<0.05$ ), whereas the chronic destructive inflammatory response which is dependent on $\mathrm{T}$ cells and mononuclear phagocytes was virtually eliminated. OA coupled to itself and administered to the SCW-injected rats had no significant effect on the acute or chronic AI which was $10.5 \pm 0.3$ on day 27, compared with $1.25 \pm 0.25$ for MC-2 (Fig. $3, P<0.05$ ). Similarly, when the control peptide containing the RGE sequence (GRGESP) was coupled to OA and injected in parallel, at the same concentrations, no inhibition of acute $(\mathrm{AI}=11 \pm 1.2)$ or chronic (AI = 8.3 \pm 1.2 ) arthritis was evident.

Inhibition of binding in vitro and in vivo by synthetic heparin-binding peptides. Based on the recent interest in the heparinbinding domain of the fibronectin A chain (15-17), we next explored the potential role of peptides synthesized from this region on leukocyte adhesion and inflammation. Peptides derived from this region (Table I) were shown to variably (4090\%) inhibit RGD-independent binding of PBMC to the 33$\mathrm{kD}$ fibronectin fragment in vitro (Fig. $4 \mathrm{~A}$ ). Moreover, as shown for $\mathrm{FN}-\mathrm{C} / \mathrm{H}-\mathrm{V}$, the most potent inhibitor of PBMC adhesion to a fibronectin matrix (Fig. $4 A$ ), the peptides also inhibited adherence to a monolayer of TNF $\alpha$-stimulated endothelial cells (Fig. $4 \mathrm{~B}$ ). A scrambled version of this peptide (Arg-Pro-GlnIle-Pro-Trp-Ala-Arg-Tyr) did not significantly block binding to the endothelial cells (Fig. 4 B, left panel) or to fibronectin (Fig. $4 \mathrm{~B}$, right panel) demonstrating the specificity of the fibronectin interactions and prompting subsequent studies to determine whether these peptides were active in vivo.

The synthetic peptides were administered individually to arthritic rats according to the protocol used for RGD-containing peptides. Beginning from the carboxy-terminal end (Fig. $5 \mathrm{~A}$ ), CS-1, FN-C/H-II, FN-C/H-I, FN-C/H-V, and FN-C/H-IV were injected i.v. at the initiation of arthritis (day 0). The CS-1 pep-

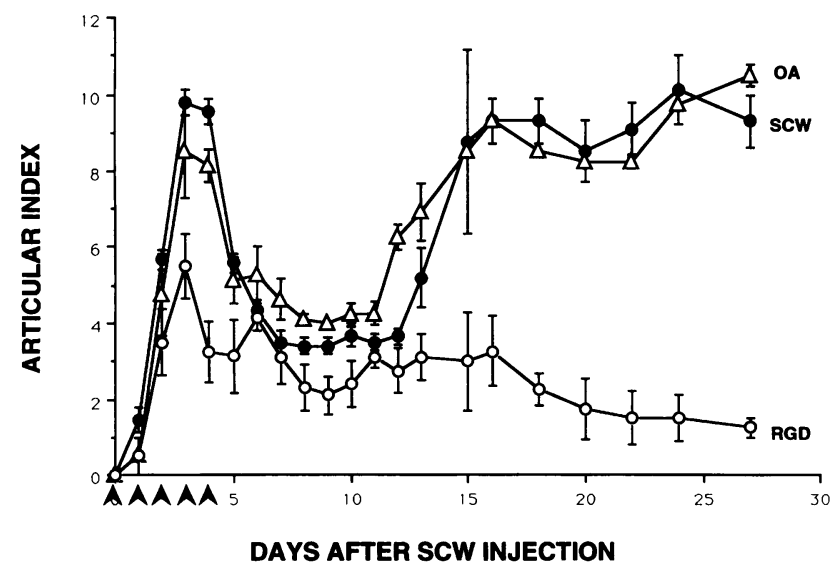

Figure 3. Inhibition of arthritis by a RGD-containing fibronectin peptide. OA-coupled to OA $(O A)$ or the RGD-containing MC-2 peptide coupled to OA were administered i.v. on days 0-4 (arrows) to SCW-injected rats. Mean articular indices \pm SE were determined at indicated intervals for individual groups of animals $(n=4-12 /$ point $)$.
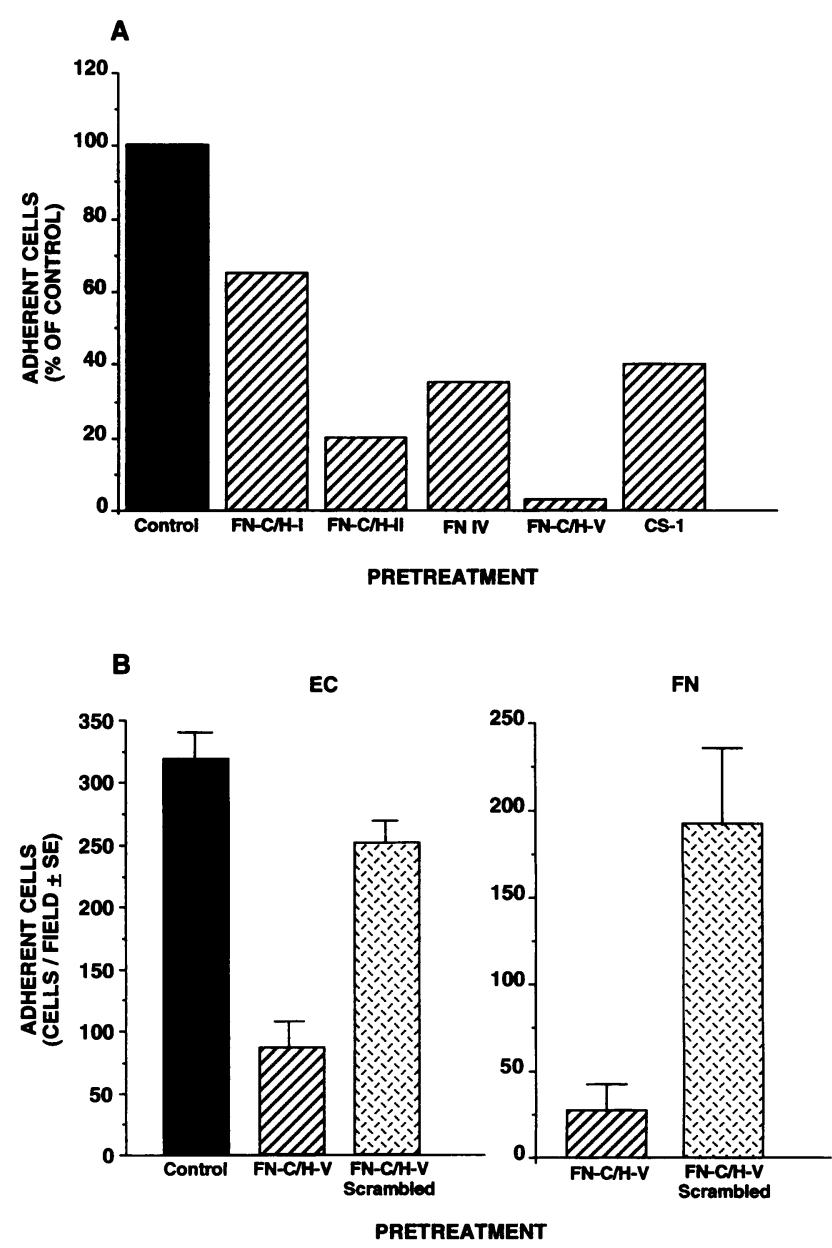

Figure 4. Inhibition of cell adhesion to fibronectin and endothelial cell monolayers by synthetic peptides. PBMC $(A)$ and spleen cells $(B)$ were incubated with $10 \mu \mathrm{g} / \mathrm{ml}$ of the indicated peptides for $15 \mathrm{~min}$ before addition of the cells to a fibronectin substrate or a TNF $\alpha$-treated $(2.2$ $\mu \mathrm{g} / \mathrm{ml}$ for $4 \mathrm{~h}$ ) endothelial cell (EC) monolayer. Peptide FN-C/H-V (100 $\mu \mathrm{g} / \mathrm{ml}$ ) was used in its normal or a scrambled configuration (Arg-ProGln-Ile-Pro-Trp-Ala-Arg-Tyr) (B).

tide was found to suppress both acute and chronic inflammation (day $3, \mathrm{AI}=5.6 \pm 0.8$ vs $9.79 \pm 0.33$ and on day $27, \mathrm{AI}$ $=2.5 \pm 0.7$ vs $10.5 \pm 0.3, P<0.02$ ). Furthermore, as shown in Fig. $5 B$, FN-C/H-I, -II and -V partially suppressed acute synovitis. Even though treatment was limited to the acute phase (day 0-4), suppression was maintained during the chronic phase, with these peptides decreasing the arthritic response $\sim 80 \%$ (FN-C/H-I, -II, and -V, $P<0.02$ ). In contrast, FN-C/H-IV, the peptide most distal from the carboxy terminal end (Fig. $5 A$ ), had minimal or no anti-arthritic properties (Fig. $5 B$ ). No evidence of toxicity based on weight loss or hematocrit levels was observed in any of the peptide-treated groups. Furthermore, sera collected on day 28 after the induction of arthritis in animals treated or not with peptides for $5 \mathrm{~d}$ contained no detectable antibodies to fibronectin or to the peptides as determined by ELISA (17).

To determine if the peptides could influence the course of the arthritis once established, arthritic animals were randomized and i.v. peptide administration initiated on day 11 and continued daily for $5 \mathrm{~d}$. Under these conditions, not only were the RGDcontaining (MC-2) and CS-1 peptides anti-inflammatory (on 
day $28, \mathrm{AI}=4.2 \pm 1.5$ for $\mathrm{CS}-1$ and $\mathrm{AI}=2.7 \pm 1.9$ for $\mathrm{MC}-2$ compared with $11.3 \pm 0.5$ for untreated arthritic animals; $P$ $<0.02$ for CS-1 and MC-2), but peptides FN-C/H-I, II and V from the heparin-binding domain also suppressed evolution of the chronic lesions (Fig. 6). FN-C/H-I was particularly effective in the chronic phase reducing the AI to $1.5 \pm 1.0(P<0.02)$. Based on these data, it would appear that lymphocytes and/or monocytes which are responsible for the events occurring in the chronic phase of arthritis $(19,21)$ must be a primary target of the peptide inhibition.

Synthetic peptides inhibit the histopathogenesis of SCWinduced arthritis. Dissemination of SCW to synovia triggers a characteristic pattern of leukocyte infiltration, synovial cell lining hyperplasia and villus formation, bone erosion, and ultimately, joint destruction $(19,21)$. After $5 \mathrm{~d}$ of peptide administration, the joints exhibited markedly reduced histopathology, often appearing normal, when evaluated 3 wk later (Fig. 7). Decreased infiltration of inflammatory cells was clearly evident in those tissues representing animals with decreased therapeutic indices as is shown for animals treated with FN-C/H-V (Fig. 7 $B$ ). Although reduction in synovial hyperplasia and erosive lesions may be secondary to the reduced leukocyte infiltrate, it may also reflect decreased activation of infiltrating cells. In

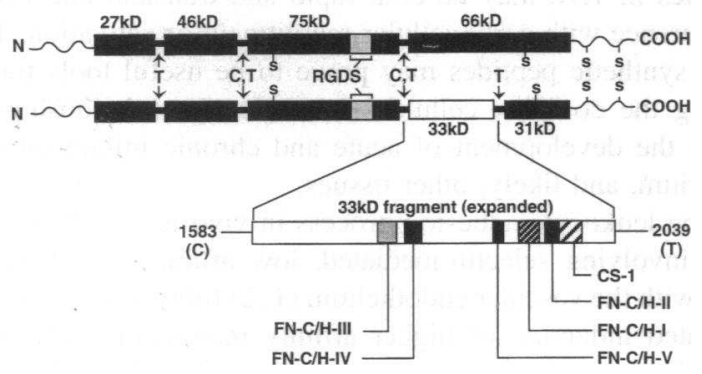

B

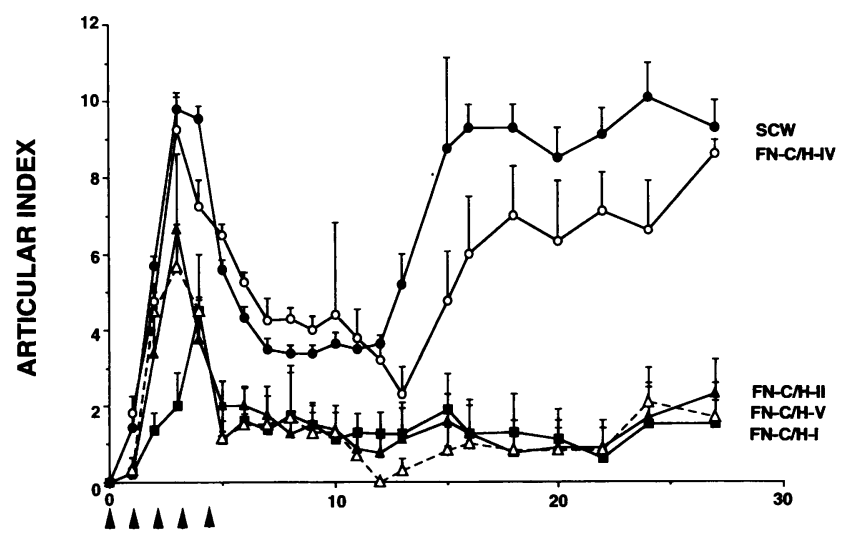

DAYS AFTER SCW INJECTION

Figure 5. Peptides synthesized from the fibronectin cell and heparinbinding domain inhibit arthritis. (A) Location of synthetic peptide sequences in the cell and heparin binding $(F N-C / H)$ fragment of the fibronectin A chain. (B) OA-coupled peptides FN-C/H-I, II, IV and V were administered i.v. on days 0-4 (arrows) to SCW-injected rats. Mean articular indices $\pm S E$ were determined at indicated intervals.

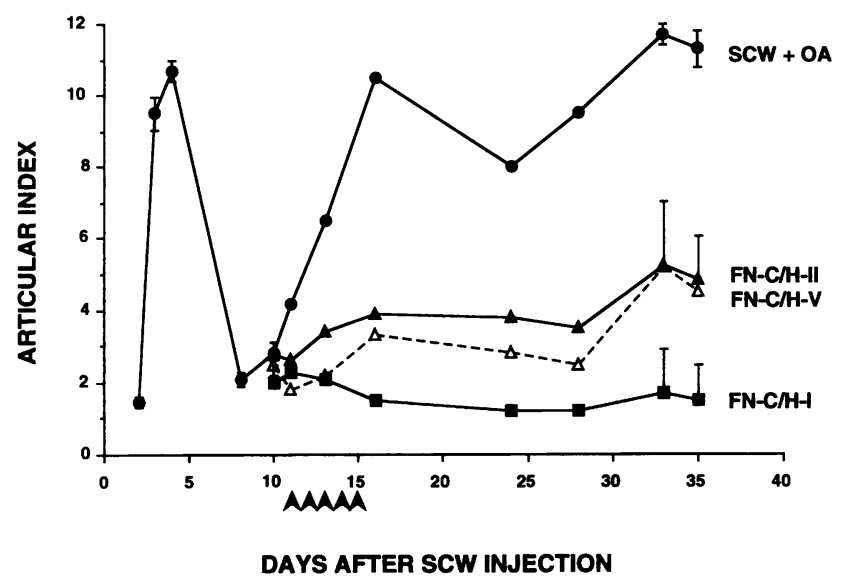

Figure 6. Inhibition of arthritis by peptide treatment initiated after the onset of arthritis. Animals were injected with SCW (day 0) and $11 \mathrm{~d}$ later, the animals were randomized for a 5-d treatment regimen (i.v.) with FN-C/H-I, FN-C/H-I, FN-C/H-V or OA coupled to OA. Mean articular indices $\pm \mathrm{SE}$ were determined at the indicated intervals.

contrast, the OA-treated, SCW-injected rats exhibited the destructive joint abnormalities characteristic of untreated arthritic animals (Fig. $7 \mathrm{~A}$ ). Delayed administration of the peptides until the early chronic phase of disease also decreased the cellular infiltrate and destructive pathology when analyzed after $4 \mathrm{wk}$ (not shown), reflecting the reduced articular index.

Effect of uncoupled peptides on the development of SCWinduced arthritis. Although coupling of the peptides to OA prolongs their circulating half-life and most likely their efficacy, it was of interest to determine whether uncoupled peptides would have any effect in vivo. Daily i.v. administration of free peptides for $5 \mathrm{~d}$ revealed an inhibitory effect on the development and maintenance of arthritis. The acute phase was variably suppressed by the peptides, but the effect was sustained in the absence of further treatment into the chronic phase (Fig. 8). Although generally less effective than coupled peptides, the free peptides were active and FN-C/H-II appeared to work as well in the uncoupled state as it did conjugated to OA.

\section{Discussion}

Understanding the molecular basis of inflammatory cell recruitment mechanisms is fundamental to developing strategies to control tissue damage and dysfunction associated with persistent inflammatory events. The current studies demonstrate that certain bioactive adhesive peptides from fibronectin can be used to inhibit a pathologic immune response to peptidoglycan-polysaccharide complexes in a rodent arthritis model $(19,21)$. The intravenous injection of fibronectin-specific peptides to rats given arthritogenic doses of SCW impaired the entry of leukocytes into the synovium and consequently, degradation of the extracellular matrix. The peptides were efficacious whether administered at $300 \mu \mathrm{g} / \mathrm{d}$ for $5 \mathrm{~d}$ at the onset of the disease, or for a 5-d regimen after disease was established. Treatment with the integrin-binding RGD or CS-1 peptides resulted in partial attenuation of the acute inflammatory response, with an almost complete blockade of the chronic inflammatory events that occur in the joints of these animals in response to SCW localization. Additionally, three cell adhesion-promoting, heparin-bind- 

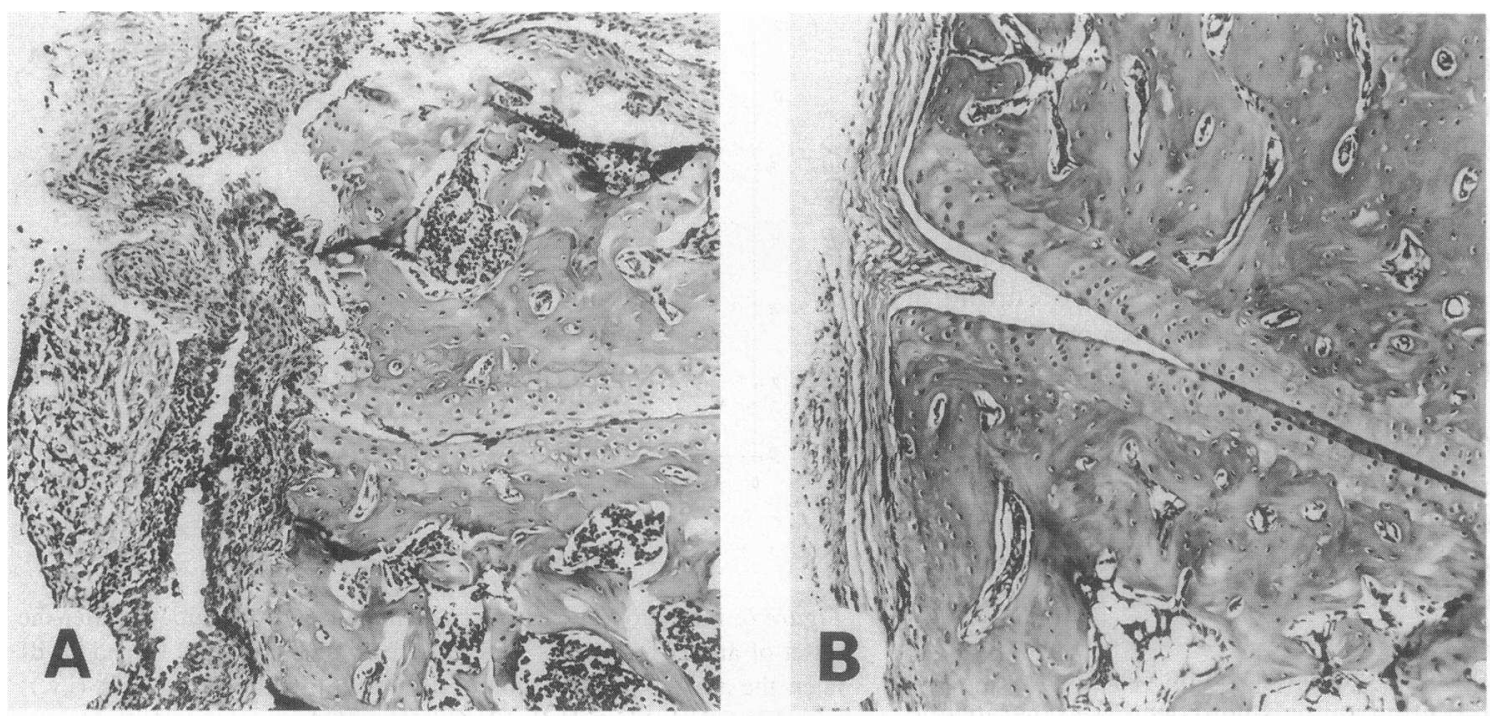

Figure 7. Reduced histopathology after FN peptide treatment. SCW was administered i.p. on day 0 and the animals injected i.v. with OA $(A)$ or with FN-C/H-V coupled to OA $(B)$ daily from day 0 through day 4 . After 3 wk, the synovial tissues were collected and processed for light microscopy. Original magnification $\times 10$.

ing synthetic peptides, referred to as $\mathrm{FN}-\mathrm{C} / \mathrm{H}-\mathrm{I}, \mathrm{FN}-\mathrm{C} / \mathrm{H}-\mathrm{II}$, and FN-C/H-V $(15,17,20,26-31)$ exhibited anti-inflammatory properties. However, another synthetic peptide derived from the heparin-binding domain, FN-C/H-IV, had no significant effect, despite the fact that it could partially inhibit leukocyte adhesion in vitro, indicating that the protective activity of the other synthetic peptides was not due to nonspecific cationic charge properties.

While we have not yet evaluated the pharmacokinetics of the peptide-OA conjugates, our results indicate that these conjugates either persist in the circulation and/or enter the synovial cavity in sufficient amounts to interrupt adhesion events critical

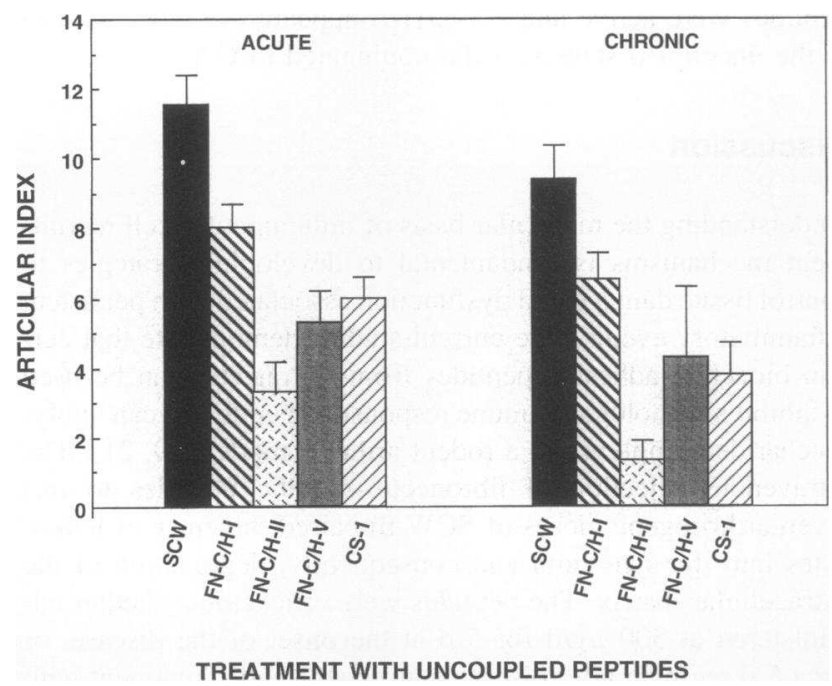

Figure 8. Inhibition of arthritis by uncoupled peptides from the heparinbinding region of fibronectin. Uncoupled peptides FN-C/H-I, II, V and CS-1 were injected i.v. daily from day 0 through day 4 and the AI monitored during the acute (day 4) and chronic (day 27) phases of arthritis. Data represent the mean $\pm \mathrm{SE}$ of four animals per group. to leukocyte accumulation and the development of inflammation. However, coupling of the peptides to OA was not required to observe a protective effect implying that the action of the peptides in vivo may be both rapid and transient and involve interference with early cellular recruitment or activation. Thus, these synthetic peptides may prove to be useful tools for dissecting the complex cellular and molecular relationships between the development of acute and chronic inflammation in synovium, and likely, other tissues.

The leukocyte adhesion process in vivo is a multistep process, involving selectin-mediated, low affinity initial interactions with the vascular endothelium $(1,2)$ followed by cytokinemediated induction of higher affinity interactions determined by leukocyte $\beta_{2}$ and $\beta_{1}$ integrins (3-6). Although much emphasis has been placed on the $\beta_{2}$ integrin (Mac-1, LFA-1):ICAM1 interactions in mediating leukocyte recruitment to sites of inflammation $(32,33)$ and the potential value of blocking this interaction in the control of leukocyte emigration (33-35), the ability of RGD and CS-1 synthetic peptides to block inflammation provides compelling evidence that synovial colonization by leukocytes may also be regulated by $\beta_{1}$ integrins.

Fibronectin-binding, $\beta_{1}$ subunit-containing integrins are upregulated on monocytes following challenge with inflammatory mediators such as TGF- $\beta$ (24), and T cells also express augmented levels of $\alpha_{5} \beta_{1}, \alpha_{4} \beta_{1}$, and $\alpha_{6} \beta_{1}$ after activation (36). Furthermore, memory T cells express higher levels of $\alpha_{4} \beta_{1}$ and $\alpha_{5} \beta_{1}$ integrin compared to naive CD4 + T cells (36) that increase after activation. Moreover, the ability of RGD to block inflammation, along with the increased levels of $\alpha_{5} \beta_{1}$ integrin observed in SCW-activated PBMC suggests a role for $\alpha_{5} \beta_{1}-\mathrm{fi}-$ bronectin interactions in mediating synovitis. While the exact mechanism(s) by which RGD may protect SCW-challenged animals is not known, in addition to blocking adhesion, RGD may interfere with fibronectin-mediated leukocyte chemotaxis (37) and nuclear activation signals, including AP-1 or IL-2 gene expression (38). The protective effects of RGD in this model system are likely pleiotropic, since several integrins have been shown to be RGD dependent (39). 
In contrast to the RGD-dependent integrins, $\alpha_{4} \beta_{1}$ is unique in that it can function as both a fibronectin receptor and a cellcell adhesion receptor. In addition to its specificity for the CS1 domain of the fibronectin molecule, $\alpha_{4} \beta_{1}$ binds to VCAM, an immunoglobulin superfamily adhesion receptor expressed on the apical surface of endothelial cells activated in vitro with TNF or IL-1 $(40,41)$, or in vivo as the result of the development of inflammatory responses (42). There is evidence that the synthetic CS-1 peptide can inhibit leukocyte adhesion to high endothelial venules (43) as well as to activated endothelial cells in vitro. Consistent with these studies, pretreatment of immune $T$ cells with the peptide sequence Gly-Pro-Glu-Ile-Asp-Val-ProSer-Thr has been shown to inhibit their ability to transfer specific contact hypersensitivity (44). In our studies, systemic administration of CS-1 blocks development of synovial inflammation. Whether CS-1 blocks at the level of $\alpha_{4} \beta_{1}$ :VCAM or $\alpha_{4} \beta_{1}$ : fibronectin interactions or both is unclear, since $\alpha_{4} \beta_{1}$ may interact with VCAM and fibronectin by distinct molecular mechanisms (41). In a cardiac allograft rejection model, blocking VCAM adhesion alone was not sufficient (42), since the use of anti-VCAM antibodies did not alter the course of cardiac rejection. Regardless of the exact mechanism(s), the current studies demonstrate that synthetic peptides can be used to interfere with the function of $\alpha_{4} \beta_{1}$ on activated leukocytes and to interrupt leukocyte recruitment and activation.

Less clear are the molecular mechanism(s) by which the peptides, FN-C/H-I, FN-C/H-II and $\mathrm{FN}-\mathrm{C} / \mathrm{H}-\mathrm{V}$, derived from the fibronectin carboxyl terminal heparin-binding domain (20, $30,31)$ act to inhibit the inflammatory process. Based on our in vitro data, these peptides inhibit circulating leukocyte adhesion to extracellular matrix and to endothelial cells which would effectively impair their retention and accumulation in the inflamed synovium. In addition, these peptides may also block signal transduction pathways and cytokine presentation. All three peptides are located in fibronectin type III repeat number $14\left(\mathrm{fnIII}_{14}\right)$, and as a result are in proximity to one another and to CS-1, found in the type IIIcs domain immediately following fnIII $_{14}$ in certain isoforms. These peptides are cationic and hydrophilic, and adhere to cell surface proteoglycans on various cell types $(27-29,31,45)$. However, since recent evidence suggests that $\mathrm{FN}-\mathrm{C} / \mathrm{H}-\mathrm{I}$ and $\mathrm{FN}-\mathrm{C} / \mathrm{H}-\mathrm{II}$ may also influence the function of $\alpha_{4}$ subunits (17), and $\mathrm{FN}-\mathrm{C} / \mathrm{H}-\mathrm{V}$ inhibits adhesion to VCAM (unpublished observations), their protective effect may involve interference with both proteoglycan binding and $\alpha_{4} \beta_{1}$ integrins. Interestingly, the active site of $\mathrm{FN}-\mathrm{C} / \mathrm{H}-\mathrm{II}$ is also present in L-selectin (29), and it is possible that this peptide may inhibit selectin-mediated binding to heparin-like structures on endothelial cells (46), as well as inhibit the action of integrins and/or proteoglycans on leukocytes. Another mechanism of action may be related to the ability of these peptides to interfere with proteoglycan-dependent presentation of inflammatory cytokines (MIP-1 $\beta$ ) by activated endothelial cells (47). Since the peptides can be delivered during the first few days after induction of arthritic lesions and their effects persist into the chronic stage, it is likely that the peptides are interrupting an early, but critical event responsible for the evolution of chronic inflammation. In this model, that critical event may be the initial $\mathrm{T}$ cell recruitment and activation, since the chronic destructive phase of the synovial inflammation is T cell dependent $(21,48)$. While these results emphasize the complex pathways whereby adhesion molecules may dictate recruitment and effector functions of inflammatory cells, they also provide the first evidence that receptors which interact with sites on the carboxyl terminal heparin-binding region of fibronectin (49) may be fundamentally important in these events.

Although the role of integrins and other cell adhesion molecules in mediating the arrest and adhesion of inflammatory cells associated with extravasation is complex and poorly understood, emerging evidence suggests that agents that inhibit or modulate this mandatory adhesion process may provide a mechanism to regulate inflammation and its associated disorders. Understanding the structural/functional properties of protective peptides will offer insight into the mechanisms by which the active sequences provide an effective barrier to the pathology associated with the continued recruitment and/or activation of inflammatory leukocytes in the arthritic synovium. In this regard, the ability of synthetic fibronectin peptides to block leukocyte recruitment into the synovium when administered at the initiation of inflammation is important, but perhaps more significant is the ability of these peptides to interrupt adhesion and recruitment in ongoing disease.

\section{Acknowledgments}

The authors are grateful to Ms. C. Tucker for technical assistance, Mr. C. Romann for data analysis, and Ms. K. Jager and Ms. Kiki Angelis for manuscript preparation.

Keith M. L. Hines is a Pharmacology Research Associate Trainee (PRAT) Fellowship recipient of the National Institute of General Medical Sciences. This work was supported in part by National Institutes of Health grants CA43924 (J. B. McCarthy) and CA21463 (L. T. Furcht).

\section{References}

1. Lasky, L. A. 1992. Selectins: Interpreters of cell-specific carbohydrate information during inflammation. Science (Wash. DC). 258:964-969.

2. Bevilacqua, M. P., and R. M. Nelson. 1993. Selectins. J. Clin. Invest. 91:379-387.

3. Ruoslahti, E. 1991. Integrins. J. Clin. Invest. 87:1-5.

4. Hynes, R. O. 1987. Integrins: a family of cell surface receptors. Cell. 48:549-554.

5. Springer, T. A. 1990. Adhesion receptors of the immune system. Nature (Lond.). 346:425-434.

6. Albeda, S. M., and C. A. Buck. 1990. Integrins and other cell adhesion molecules. FASEB (Fed. Am. Soc. Exp. Biol.) J. 4:2868-2880.

7. Akiyama, S. K., and K. M. Yamada. 1987. Fibronectin. Adv. Enzymol. 57:1-57.

8. Brown, P. J., and R. L. Juliano. 1985. Selective inhibition of fibronectinmediated adhesion by monoclonal antibodies to a cell surface glycoprotein. Science (Wash. DC). 228:1448-1451.

9. Elices, M. J., L. A. Urry, and M. E. Hemler. 1991. Receptor functions for the integrin VLA-3: Fibronectin, collagen, and laminin binding are differentially influenced by ARG-GYL-ASP peptide and by divalent cations. J. Cell Biol. 112:169-181.

10. Guan, J. L., and R. O. Hynes. 1990. Lymphoid cells recognize an alternatively spliced segment of fibronectin via the integrin receptor alpha $4 /$ beta 1 . Cell. 60:53-61.

11. Butcher, E. C. 1991. Leukocyte-endothelial cell recognition: three (or more) steps to specificity and diversity. Cell. 67:1033-1036.

12. Osborn, L. 1990. Leukocyte adhesion to endothelium in inflammation. Cell. 62:3-6.

13. Hemler, M. E. 1990. VLA proteins in the integrin family: structures, functions, and their role in leukocytes. Annu. Rev. Immunol. 8:365-400.

14. Shimizu, Y., G. A. Van Seventer, K. J. Horgan, and S. Shaw. 1990. Costimulation of proliferative responses of resting CD4 $+\mathrm{T}$ cells by interaction of VLA4 and VLA5 with fibronectin or VLA6 with laminin. J. Immunol. 145:5967.

15. McCarthy, J. B., A. P. N. Skubitz, Q. Zhao, X-Y. Yi, D. J., Mickelson, and L. T. Furcht. 1990. RGD-independent cell adhesion to the carboxy-terminal heparin binding fragment of fibronectin involves heparin-dependent and -independent activities. J. Cell Biol. 110:777-787.

16. Liao, N., J. S. John, J. B. McCarthy, L. T. Furcht, and H. T. Cheung. 1989. 
Adhesion of lymphoid cell to the carboxyl-terminal heparin-binding domains of fibronectin. Exp. Cell Res. 181:348-361.

17. lida, J., A. P. N. Skubitz, L. T. Furcht, E. A. Wayner, and J. B. McCarthy 1992. Coordinate role for cell surface chondroitin sulfate proteoglycan and $\alpha_{4} \beta$ integrin in mediating melanoma cell adhesion to fibronectin. J. Cell Biol. 118:431 444.

18. Hines, K. L., J. B. Allen, T. Imamichi, J. B. McCarthy, L. T. Furcht, and S. M. Wahl. 1993. Fibronectin peptides inhibit inflammatory cell infiltration and arthritis. J. Immunol. 150:139A.

19. Skaleric, U., J. B. Allen, P. D. Smith, S. E. Mergenhagen, and S. M Wahl. 1991. Inhibitors of reactive oxygen intermediates suppress bacterial cell wall-induced arthritis. J. Immunol. 147:2559-2564.

20. McCarthy, J. B., M. K. Chelberg, D. J. Mickelson, and L. T. Furcht. 1988. Localization and chemical synthesis of fibronectin peptides with melanoma adhesion and heparin binding activities. Biochemistry. 27:1380-1388.

21. Brandes, M. E., J. B. Allen, Y. Ogawa, and S. M. Wahl. 1991. Transforming growth factor $\beta_{1}$ suppresses acute and chronic arthritis in experimenta animals. J. Clin. Invest. 87:1108-1113.

22. Chomczynski, P., and N. Sacchi. 1987. Single step method of RNA isolation by acid guanidinum thiocyanate-phenol-chloroform extraction. Anal. Bio chem. 162:156-160.

23. Piecharczyk, M., J. M. Blanchard, M. L. Dani, C. Panabieres, F. El Sabouty, S. Fort, and P. H. Jeanteur. 1984. Post-transcriptional regulation of glyceraldehyde- 3 phosphate-dehydrogenase gene expression in rat tissues. Nucleic Acids Res. 12:6951-6959.

24. Wahl, S. M., J. B. Allen, B. S. Weeks, H. L. Wong, and P. Klotman 1993. TGF- $\beta$ enhances integrin expression and type IV collagenase secretion in human monocytes. Proc. Natl. Acad. Sci. USA. 90:4577-4581.

25. Hines, K. L., A. B. Kulkarni, J. B. McCarthy, H. Tian, J. M. Ward, M. C. Christ, N. L. McCartney-Francis, L. T. Furcht, S. Karlsson, and S. M. Wahl. 1994. Synthetic fibronectin peptides interrupt inflammatory cell infiltration in TGF- $\beta 1$ knockout mice. Proc. Natl. Acad. Sci. USA. 91:5187-5191.

26. Haugen, P. K., J. B. McCarthy, A. Skubitz, L. T. Furcht, and P. C. Letourmeau. 1990. Recognition of the A chain carboxyl terminal heparin binding region of fibronectin involves multiple sites: two contiguous sequences act independently to promote neural cell adhesion. J. Cell Biol. 111:2733-2745.

27. Haugen, P. K., P. C. Letourneau, S. Drake, L. T. Furcht, and J. B. McCarthy. 1992. A cell-surface heparin sulfate proteoglycan mediates neural cell adhesion and spreading on a defined sequence from the C-terminal cell and heparin binding domain of FN, FN-C/H II. J. Neurosci. 12:2597-2608.

28. Drake, S., D. J. Klein, D. J. Mickelson, T. R. Oegema, L. T. Furcht, and J. B. McCarthy. 1992. Cell surface phosphatidylinositol-anchored heparin sulfate proteoglycan initiates mouse melanoma cell adhesion to a fibronectin-derived, heparin binding synthetic peptide. J. Cell Biol. 117:1331-1341.

29. Drake, S. L., J. Varnum, K. H. Mayo, P. C. Letourneau, L. T. Furcht, and J. B. McCarthy. 1993. Structural features of fibronectin synthetic peptide FN-C/ $\mathrm{H}$ II, responsible for cell adhesion, neurite extension, and heparan sulfate binding. J. Biol. Chem. 268:15859-15867.

30. Mooradian, D. L., J. B. McCarthy, A. P. N. Skubitz, D. J. Cameron, and L. T. Furcht. 1993. Characterization of FN-C/H-V, a novel synthetic peptide from fibronectin that promotes rabbit corneal epithelial cell adhesion, spreading, and motility. Invest. Opthalmol. \& Visual Sci. 34:153-164.

31. Woods, A., J. B. McCarthy, L. T. Furcht, and J. R. Couchman. 1993. Selective ability of synthetic peptides from the COOH-terminal heparin-binding domain of fibronectin to promote focal adhesion formation. Mol. Biol. Cell. 4:605613.
32. Isobe, M., H. Yagita, K. Okumura, and A. Ihara. 1992. Specific acceptance of cardiac allograft after treatment with antibodies to ICAM-1 and LFA-1. Science (Wash. DC). 255:1125-1127.

33. Mulligan, M., C. W. Smith, D. C. Anderson, R. F. Todd III, M. Miyasaka, T. Tamatani, T. B. Issekutz, and P. A. Ward. 1993. Role of leukocyte adhesion molecules in complement-induced lung injury. J. Immunol. 150:2401-2406.

34. Barton, R., R. Rothlein, J. Ksiazek, and C. Kennedy. 1989. The effect of anti-intercellular adhesion molecule-1 on phorbol-ester-induced rabbit lung inflammation. J. Immunol. 143:1278-1282.

35. Conti, D., and B. Cosimi. 1990. Effect of monoclonal antibodies on primate allograft rejection. Crit. Rev. Immunol. 109:113.

36. Shimizu, Y., G. A. van Seventer, K. J. Horgan, and S. Shaw. 1990. Roles of adhesion molecules in $\mathrm{T}$-cell recognition: fundamental similarities between four integrins on resting human T cells (LFA-1, VLA-4, VLA-5, VLA-6) in expression, binding and costimulation. Immunol. Rev. 114:109.

37. Tsukamoto, Y., W. E. Helsel, and S. M. Wahl. 1981. Macrophage production of fibronectin, a chemoattractant for fibroblasts. J. Immunol. 127:673-678.

38. Yamada, A., T. Nikaido, Y. Nojima, S. F. Schlossman, and C. Morimoto. 1991. Activation of human CD4 T lymphocytes. Interaction of fibronectin with VLA-5 receptor on CD4 cells induces the AP-1 transcription factor. J. Immunol. 146:53-56.

39. Faassen, A. E., S. L. Drake, J. Iida, F. R. Knutson, and J. B. McCarthy. 1992. Mechanisms of normal cell adhesion to the extracellular matrix and alterations associated with tumor invasion and metastasis. In Advances in Pathology and Laboratory Medicine. R. S. Weinstein and A. R. Graham, editors. MosbyYear Book, Vol. 5. 229-259.

40. Osborn, L., C. Hession, R. Tizard, C. Vassallo, S. Luhowskyj, M. J. Hemler, and R. Lobb. 1989. Direct expression cloning of vascular cell adhesion molecule 1, a cytokine-induced endothelial protein that binds to lymphocytes. Cell. 59:1203-1211.

41. Elices, M. J., L. Osborn, Y. Takada, C. Crouse, S. Luhowskyj, M. J. Hemler, and R. Lobb. 1990. VCAM-1 on activated endothelial interacts with the leukocyte integrin VLA-4 at a site distinct from the VLA-4/fibronectin binding site. Cell. 60:577-584

42. Pelletier, R. P., R. G. Ohye, A. Vansbuskirk, D. D. Sedmak, P. Kincade, R. M. Ferguson, and C. G. Orosz. 1992. Importance of endothelial VCAM-1 for inflammatory leukocytic infiltration in vivo. J. Immunol. 149:2473-2481.

43. Ager, A., and M. J. Humphries. 1990. Use of synthetic peptides to probe lymphocyte-high endothelial cell interactions. Lymphocytes recognize a ligand on the endothelial surface which contains the CS1 adhesion motif. J. Immunol. 142:318.

44. Ferguson, T. A., H. Mizutani, and T. S. Kupper. 1991. Two integrinbinding peptides abrogate $\mathrm{T}$ cell-mediated immune responses in vivo. Proc. Natl. Acad. Sci. USA. 88:8072-8076.

45. Jalkanen, S., and M. Jalkanen. 1992. Lymphocyte CD44 binds the carboxyl terminal heparin binding domain of fibronectin. J. Cell Biol. 116:817-825.

46. Norgard-Sumnicht, K. E., N. M. Varki, and A. Varki. 1993. Calciumdependent heparin-like ligands for L-selectin in nonlymphoid endothelial cells. Science (Wash. DC). 261:480-483.

47. Tanaka, Y, D. H. Adams, S. Hubscher, H. Hirano, U. Siebenlist, and S. Shaw. 1993. T-cell adhesion induced by proteoglycan-immobilized cytokine MIP1 beta. Nature (Wash. DC). 361:79-82.

48. Hines, K. L., M. Christ, and S. M. Wahl. 1993. Cytokine regulation of the immune response: An in vivo model. ImmunoMethods. 3:1-10.

49. Bober-Barkalow, F. J., and J. E. Schwarzbauer. 1991. Localization of the major heparin binding site in fibronectin. J. Biol. Chem. 266:7812-7818. 